Onkologe 2016 $\cdot 22: 138-139$

DOI 10.1007/s00761-016-0019-3

Online publiziert: 26. Februar 2016

(c) Springer-Verlag Berlin Heidelberg 2016

CrossMark

Klaus Höffken ${ }^{1}$ P Peter M. Schlag ${ }^{2}$

' Universitätsklinikum Düsseldorf, Düsseldorf, Deutschland

${ }^{2}$ Charité Comprehensive Cancer Center, Charité Campus Mitte, Berlin, Deutschland

\title{
Es muss sich immer etwas ändern, damit alles so bleibt wie es ist
}

Mit dieser kleinen Abänderung des Originalzitats von Giuseppe Tomasi di Lampedusa aus seinem Buch „Der Leopard“ möchten sich Herausgeber und Verlag von Herrn Prof. Dr. Michael Bamberg als einem der 3 Gründungsherausgeber der Fachzeitschrift Der Onkologe verabschieden. Prof. Bamberg verlässt nach 20-jähriger Mitarbeit die Schiffsbrücke, um dem Vertreter der Radioonkologie aus der nächsten Generation, Herrn Prof. Dr. Heinz Schmidberger, den Platz zu übergeben. Die Zeitschrift verliert damit einen der herausragenden Vertreter der deutschen Radioonkologie als Mitherausgeber. Prof. Bamberg hat der Zeitschrift Der Onkologe stets seine volle fachliche Aufmerksamkeit - ja einen Teil seines Herzbluts - gewidmet und war Garant für die Interdisziplinarität der Schwerpunkthefte und deren Beiträge. Mit dem ihm eigenen Enthusiasmus und Engagement hat er über die vielen Jahre entscheidend zum Erfolg und Ansehen der Fachzeitschrift beigetragen. Wir sind ihm zu großem Dank verpflichtet!

Wer Michael Bamberg, seinen Lebensweg und seine Lebensplanung kennt, weiß, dass er die Position des Mitherausgebers nicht aus Müdigkeit verlässt, sondern in der Erkenntnis, dass man die Zukunftsfähigkeit eines Konzepts durch regelmäßige Erneuerungen sichert. Insofern respektieren wir als die beiden weiter in der Verantwortung für Qualität und Aktualität der Fachzeitschrift stehenden Mitherausgeber den Schritt unseres Kollegen. Auch wir werden zur hoffentlich rechten Zeit den Stab an jüngere Fachvertreter übergeben. Damit aber Wandel mit Kontinuität die zukünftige Gestal- tung „unserer“ Zeitschrift prägt, freuen wir uns auf die gemeinsame Arbeit mit dem neuen Mitherausgeber Herrn Kollegen Heinz Schmidberger und werden gemeinsam weiter unser Bestes geben, um die Erwartungen der Leserschaft von Der Onkologe zu erfüllen.

Klaus Höffken

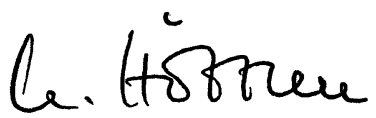

Peter M. Schlag

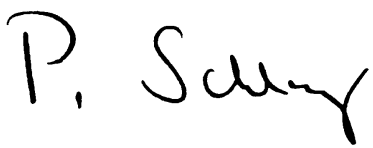

\section{Korrespondenzadresse}

\section{K. Höffken}

Universitätsklinikum Düsseldorf Moorenstr. 5, 40225 Düsseldorf, Deutschland Klaus.Hoeffken@med.uni-duesseldorf.de

Interessenkonflikt. K. Höffken und P. Schlag geben an, dass kein Interessenkonflikt besteht. 
Hier steht eine Anzeige.

算 Springer 